ence has proved that Western methods of birth control can scarcely be used in such conditions. Moreover, however much some of the people concerned would like to have small families, most of them are either too ignorant or too resigned even to take the trouble to understand the simple facts that are involved in human reproduction. Great efforts have been made in a few areas to overcome these obstacles; but so far with results that are trivial in relation to the size of the problem.

The situation would obviously be transformed if the 'pill' were ever discovered. But the 'pill' would need to be essentially 100 per cent certain, and commercialization would have to be resisted until the most rigorous clinical trials had been carried out, and until it had been shown that there was no danger of any long-term deleterious effects. The Asian peoples are not provided with lavish medical services, and it would be unthinkable to encourage the use of a drug which was not virtually certain in its action, if its failure meant that a medical man would have to be called in. Moreover, if the drug only affected germ cells or an embryo deleteriously, without destroying them fully, the results could be even more disastrous to the future than the unrestrained growth of population. The West will, therefore, be hurting, not helping, the underdeveloped areas of the world, and would be doing irremediable harm to the good name of Western physiological science, if a 'pill' were launched upon the world before its capacity to satisfy all the desiderata, scientific and social, had been established. But the West will be doing nothing but good if it continues to press on with the kind of physiological research of which the Tokyo meeting provided so useful a résumé.

\title{
THE SCIENTIFIC WORK OF BENJAMIN FRANKLIN
}

\author{
By Prof. E. N. da C. ANDRADE, F.R.S.
}

$I^{N}$ N. 1746 Benjamin Franklin received from Peter Collinson, of London, a glass tube suitable for carrying out experiments on frictional electricity, with directions as to how to use it*. He set to work on the subject with enthusiasm, writing "For my own part, I never was before engaged in any study that so totally engrossed my attention and my time as this has lately done". He was thus forty years of age (having been born on January 17, N.S., 1706) when he first took up the subject which was to make his name immortal in the world of science, and for seven full years thereafter he was engaged in pioneering experiment, shrewd deduction and simple but penetrating theory. Tho results of his electrical researches were cornmunicated in a series of letters, beginning in 1747, to Collinson, who was a Fellow of the Royal Society. The publication of these letters as a book in 1751 made Franklin famous throughout Europe and two supplements were issued, the last in 1754. In 1757 Franklin came to England as official representative of the American Colonies, and after that date, although he continued to take a lively, stimulating and practical interest in scientific matters, the pressure of his public duties as a negotiator and statesman made the systematic pursuit of experiment impossible.

One of Franklin's earliest observations, of which he made full use, was on the power of a metal point to discharge an electrified conductor, in his case a large shot insulated by being placed on a clean, dry glass bottle. He generously acknowledged that the first experiment was made by his friend Hopkinson, who, apparently, did nothing to follow it up. If a pointed bodkin was attached to the shot it rapidly lost its charge, as it also did if the bodkin, earthed by being held in the hand, was presented, even at a distance of 8 in., to the shot. If the bodkin was insulated, no such effect took place. He later carried out a similar experiment with a very large charged cylinder made of pasteboard covered with metal foil, when he showed that an insulated man, presenting the point of a needle, became charged. Franklin likewise observed the glow at the point that accom-

* With regard to an erroneous date given in Franklin's "Autobiography" and to the general history of Franklin's introduction to cote, N. F. de V., Isis, 46, 29 (1955). panied the discharge. He put forward an explanation of the discharge from a pointed conductor in terms of the attractive force by which the charged body retained its electrified atmosphere : at a point there was a very small attractive surface and a relative inability to hold the charge. These experiments were to lead to the lightning rod.

Very early Franklin carried out experiments in which a man on an insulating base (a block of wax) electrified a glass tube by rubbing and then communicated a charge to another man similarly insulated. By variations of circumstance, including an carth provided by a man standing on the floor, he came to the sound conclusion that, as he put it, electricity was not created by friction, but collected -that there was a separation of electricity which left behind it a corresponding defect. In consequence, he introduced the terms 'positive' and 'negative' electricity, as still used, the electricity of the rubbed glass being positive. His theory was therefore called the 'one-fluid theory'. He also brought into regular use the terms 'non-conductor' and 'conductor' (the term 'conductor' had already been used by Desaguliers) in place of 'electric per se' and 'non-electric' then in general use.

His work on the Leyden jar, which had been discovered in a primitive form by von Kleist in 1745 but brought into general notice by Musschenbroek, of Leyden, in the following year, added clarity to what was a very obscure subject. He showed that the two coatings were oppositely charged and, in particular, that one coating had to be earthed while the other was electrified. He showed the large part played by the glass in the action-in fact, he declared that the whole power of the jar to give a shock lay in the glass. The correct elucidation of the action of the dielectric had to wait for Faraday. While carrying out this work, he simplified the whole matter by making the first plane condenser, of sheets of glass between plates of lead, the so-called Franklin panes, which enabled the coatings and the glass to be readily separated and conjoined. (Franklin has a note to his Letter IV, of 1748 , "I have since heard that Mr. Smeaton was the first who made use of panes of glass for this purpose", but I have been unable to trace any record of this work of Smeaton's.) 
It was, of course, Franklin's work on lightning and the lightning-rod that was chiefly responsible for his scientific fame. He was not the first to direct attention to the resemblance of the light and sound of the electric spark to lightning and thunder. Hauksbee (1705), Wall (1708), Newton (1716) and Gray (1735) had all referred to it casually, the last-named saying, for example, "that power [electricity] which by several experiments ... seems to be of the same nature with that of thunder and lightning". It was, however, left to Franklin to show systematically that there was something more than a superficial resemblance, that thunder clouds were actually seats of electric charge which could be shown to behave like normal charges and that the action of pointed conductors, which he had so thoroughly investigated, might be used to dissipate the charge or, if this action was insignificant, to attract the lightning discharge and carry it harmlessly to earth, so as to protect buildings. He proposed what is known as the Philadelphia experiment: that a sentry box should be placed on a high building, with a long pointed rod, well insulated, protruding upwards. He anticipated that, when thunder clouds were overhead, a man in the box would be able to draw sparks from the rod by presenting to it an earthed wire, held by an insulating handle. The experiment was first carried out in France, in May 1752, by D'Alibard at Marly and by Delor in Paris independently. It met with a full success, which created a sensation, Delor obtaining sparks nearly an inch long.

It was later that Franklin carried out the famous kite experiment, described in a letter dated October 19, 1752. The lower end of the string of the kite, which became conducting when wet, was attached to a silk ribbon, which insulated it from the hand. Sparks were obtained, a Leyden jar charged and other standard electrical experiments performed. Among the last experiments made by Franklin were some on the sign of the charge on thunder clouds, which he found to be in most cases negative, although occasionally positive charges occurred, which modern observation has confirmed.

Of Franklin's design of lightning rod, pointed above and earthed below, it will suffice here to quote the modern lightning expert Dr. B. F. J. Schonland : "Franklin's specifications for the rod . . . have proved substantially correct".

Other effects of atmospheric electricity were also studied by Franklin. He recognized the aurora borealis for a phenomenon of electric discharge. $\mathrm{He}$ stated that the atmosphere at above a certain height was so rare as to be almost $\mathbf{a}$ vacuum and therefore a good conductor of electricity. The discharge he supposed caused by electrified vapours rising from the sea and proceeding to the pole, where the nonconducting nature of the ice played a part-an explanation on scientific lines at a time when greater correctness could not be expected. He may be said to have foreseen the ionosphere: "Who knows but there may be, as the Antients thought, a region of this fire [the electric 'fire'] above our atmosphere, prevented by our air, and its own too great distance for attraction, from joining our earth ?".

While it was for his experiments on electricity that Franklin was best known, these constitute by no means his only claims to consideration as a man of science. Among meteorological phenomena he was much interested in whirlwinds and waterspouts, which he recognized as due to the same cause, a very rapid local circulation of the air, with a con- sequent region of low pressure in the neighbourhood of the axis. He thought, however, that the waterspout consisted of water, whereas it is a cloud of water drops and droplets, and so was puzzled by the height, for he clearly recognized that the atmospheric pressure could not hold up a volume of water more than $30 \mathrm{ft}$. in height.

There are a host of original observations to be found in Franklin's collected papers. He makes the generalization that good conductors of heat are good conductors of electricity, long before the days of voltaic electricity. He explains that clothes keep the body warm by retaining and confining the natural heat, wool being warmer than cotton because it is a much poorer conductor. He has some penetrating remarks on the cooling produced by evaporation, from which he proceeds to explain the beneficial effects of perspiration in keeping down the body temperature in hot weather.

Everywhere his acuteness is evident. For example, he was, after looking closely into the matter, strongly in favour of inoculation against smallpox; but, after systematic trial, considered that electric shock from the discharge of a Leyden jar was of no use as a cure for paralysis and such-like ills, saying that he had never known any advantage that was permanent. This was at a time when John Wesley was writing of the most extraordinary cures, even of blindness, produced by electric shocks and when Priestley wrote that "electricity is now become a considerable article in the materia medica".

As an inventor Franklin is best known for his stove, his 'Pennsylvanian Fire-Place'. He pointed out that with the fireplaces then in use the hot air passed up the chimney, its place being taken by air coming as a violent draught through crevices, which was a great promoter of the common cold. In Franklin's invention the stove stood a foot or so in front of the wall. From the front part where the fire was burning the hot air within the stove rose to strike a horizontal plate and was then led down a pipe of rectangular cross-section, which enclosed a so-called air-box between itself and the fireplace proper. This pipe entered the chimney at floor level. The hot air thus heated the whole stove and, in particular, the sides of the air box, as well as the wall. The fresh air was supplied through a pipe under the floor. In pointing out the saving of fuel and the absence of violent draught Franklin, ever a man of sense and of the senses, directed attention to the fact that one did not lose the pleasant sight of the fire and could also use the flat top to warm flat irons or keep food warm. Among his other inventions the most familiar to-day is that of bifocal spectacles.

It may be fitting to conclude these very brief notes on Franklin's scientific work with words that appear to be little known, though spoken by one of England's greatest natural philosophers, Sir Humphry Davy. They cannot well be bettered. "The experiments adduced by Dr. Franklin in support of his hypothesis were most ingeniously contrived and happily executed. A singular felicity of induction guided all his researches, and by very small means he estab. lished very grand truths. The style and manner of his publication are almost as worthy of admiration as the doctrines it contains. He has endeavoured to remove all mystery and obscurity from the subject; he has written equally for the uninitiated and for the philosopher; and he has rendered his details amusing as well as perspicuous-elegant as well as simple". 